\title{
Efeitos da radiação ultravioleta-B sobre a morfologia foliar de Arabidopsis thaliana (L.) Heynh. (Brassicaceae)
}

\author{
Maria Regina Torres Boeger ${ }^{1,3}$ e Mary Poulson ${ }^{2}$
}

\author{
Recebido em 4/03/2005. Aceito em 12/09/2005
}

\begin{abstract}
RESUMO - (Efeitos da radiação ultravioleta-B sobre a morfologia foliar de Arabidopsis thaliana (L.) Heynh. (Brassicaceae)). A redução da camada de ozônio resulta no aumento da radiação ultravioleta que atinge a superfície terrestre, especialmente a radiação ultravioleta-B (UV-B). O aumento da radiação poderá induzir a mudanças estruturais e fisiológicas nas plantas, influenciando no seu crescimento e desenvolvimento. O objetivo deste trabalho foi determinar os efeitos da radiação UV-B ambiente sobre a morfologia das folhas de Arabidopsis thaliana desenvolvidas em condições controladas. As sementes de A. thaliana cresceram em câmaras de crescimento, com $300 \mu \mathrm{mol} \mathrm{m} \mathrm{m}^{-2} \mathrm{~s}^{-1}$ de radiação fotossinteticamente ativa (PAR) com ou sem $6 \mathrm{~kJ} \mathrm{~m}^{-2} \mathrm{~s}^{-1}$ de radiação UV-B $\mathrm{B}_{\mathrm{be}}\left(\mathrm{UV}-\mathrm{B}_{\mathrm{be}}\right.$; UV-B biologicamente efetiva). Após 21 dias, 10 folhas de cada tratamento (com e sem radiação UV-B) foram coletadas para avaliar área foliar, massa fresca e seca, AEF, densidades estomáticas e de tricomas de ambas as faces da folha, espessura da lâmina foliar e concentração de compostos fenólicos e de clorofila total, $a$ e $b$. As folhas tratadas com radiação UV-B apresentaram menor área foliar, massa fresca e seca, densidade de tricomas na face adaxial e densidade de estômatos na face abaxial da folha. Entretanto, apresentaram os maiores valores médios de espessura total da lâmina e do mesofilo, maior concentração de clorofila total, clorofila $a$ e clorofila $b$ e compostos fenólicos foliares do que as folhas não tratadas com radiação UV-B. Essas diferenças morfológicas significativas $(\mathrm{p}<0,05)$ entre as folhas tratadas e não tratadas com radiação UV-B indicam que $A$. thaliana é sensível à radiação e possui mecanismos para minimizar os seus efeitos negativos sobre o desenvolvimento e crescimento foliar. Entretanto, as respostas da planta à radiação UV-B envolvem vários mecanismos fisiológicos que ainda necessitam de investigações mais detalhadas.
\end{abstract}

Palavras-chave : Arabidopsis thaliana, radiação UV-B, morfologia foliar, compostos fenólicos

\begin{abstract}
Effects of ultraviolet-B radiation on leaf morphology of Arabidopsis thaliana (L.) Heynh. (Brassicaceae)). Reduction of the ozone layer results in the increase in ultraviolet radiation reaching the earth's surface, especially the ultraviolet-B (UV-B). The increase of radiation may induce structural and physiological changes in plants, influencing their growth and development. This paper evaluates the effects of ambient UV-B radiation upon to the leaf morphology of Arabidopsis thaliana developed under controlled conditions. The seeds of $A$. thaliana grown in environmental chamber, with $300 \mu \mathrm{mol} \mathrm{m}^{-2} \mathrm{~s}^{-1}$ de photosynthetically active radiation (PAR) with and without $6 \mathrm{~kJ} \mathrm{~m}^{-2} \mathrm{~s}^{-1}$ of radiation UV-B $\mathrm{be}_{\mathrm{be}}\left(\mathrm{UV}-\mathrm{B}_{\mathrm{be}}\right.$; UV-B biologically effective). After 21 days, ten leaves of each treatment (with and without UV-B radiation) were collected to measure leaf area, fresh and dry mass, AEF, stomata and trichome densities of both leaf surfaces, leaf thickness and concentration of phenolic compounds and total chlorophyll, and chlorophyll $a$ and $b$. Leaves treated with UV-B radiation presented smaller leaf area, fresh and dry weight, hair density, and stomata density on the adaxial epidermis. However, leaves treated with UV-B presented higher mean values for total thickness, mesophyll thickness, higher concentration of total chlorophyll, chlorophyll $a$ and $b$, and phenolic compounds when compared to leaves without UV-B radiation. These significant morphological differences $(\mathrm{p}<0.05)$ between leaves treated with and without UV-B radiation indicate that $A$. thaliana is not insensible to UV-B radiation and possess mechanisms that minimize the negative effects on leaf development and growth. Although, the plant responses to UV-B radiation involves several physiological mechanisms, that need more detailed investigation.
\end{abstract}

Key words: Arabidopsis thaliana, UV-B radiation, leaf morphology, phenolic compounds

\section{Introdução}

Nos últimos anos, a quantidade de radiação ultravioleta B (UV-B) que atinge a superfície da terra tem aumentado consideravelmente, devido à diminuição da camada de ozônio (Kerr 1993) tanto no hemisfério sul como no hemisfério norte. Esta radiação afeta de diferentes maneiras os seres vivos, tanto nos seus processos fisiológicos como na sua morfologia (Tevini \& Teramura 1989). Entre as plantas, muitas espécies respondem negativamente a ação dos UV-B, mas efeitos neutros ou positivos têm sido reportados na literatura (Correia et al. 1998; Parisi et al. 1998).

\footnotetext{
1 Universidade Federal do Paraná, Departamento de Botânica, C. Postal 19031, CEP 81530-990, Curitiba, PR, Brasil

2 Central Washington University, Department of Biological Sciences, Ellensburg, WA 98926-7537, USA (poulsonm@cwe.edu)

3 Autor para correspondência: rboeger@ufpr.br
} 
Entre os efeitos até agora observados, constatouse a diminuição na taxa de crescimento, redução da área foliar (Hao et al. 2000) e redução na absorção de luz visível, sugerindo mudanças nas características foliares (Tosserams \& Rozema 1995). Os poucos estudos que avaliaram as mudanças na morfologia foliar de plantas expostas à UV-B observaram o incremento da espessura e número de camadas de hipoderme em Pinus ponderosa Dougl. ex Laws (Nagel et al. 1998), aumento da espessura do parênquima paliçádico, concentração de cloroplastos próximos à face adaxial da epiderme, em conseqüência da redução da capacidade de transporte dos elétrons em Pisum sativum L. (Day \& Vogelmann 1995), aumento na densidade de tricomas nas folhas de diferentes espécies de Quercus (Liakoura et al. 1997) e redução na densidade dos estômatos, assim como, na abertura estomática em Oryza sativa L. (Dai et al. 1995).

$\mathrm{O}$ grau de dano que a radiação UV-B pode causar nas plantas depende da eficiência dos mecanismos de proteção e reparo, como o acúmulo de substâncias ou estruturas que absorvem a radiação, assim como, a ativação de defesas anti-oxidantes (Jansen et al. 1998; Mazza et al. 2000). Para algumas espécies, a penetração da radiação na lâmina foliar é atenuada pelas camadas epicuticulares e pela cutícula (Laakso et al. 2000) assim como pela presença de hipoderme (Day et al. 1992; Day 1993).

Adicionalmente, as plantas expostas à radiação UV-B são induzidas à mudanças bioquímicas, tais como a produção de compostos que absorvem UV-B (por exemplo: flavonóides e outros compostos fenólicos na folha) (Day 1993; Mazza et al. 2000). Os compostos que absorvem a radiação UV-B alteram as propriedades ópticas das folhas, atenuando a radiação UV-B através dos tecidos foliares, reduzindo assim significativamente o potencial da radiação em danificar o DNA, que ocorre nas células do mesofilo (Day et al. 1992; Day 1993; Hoque \& Remus 1999). Muito dos experimentos com radiação UV-B utilizam doses altas (mais do que duas vezes as doses ambientais) (Stapleton 1992; Jordan 1996). Estudos com doses menores de radiação UV-B indicam que a mesma pode não ser prejudicial ao crescimento ou produtividade de algumas espécies (Allen et al. 1998) e ainda pode estimular a tolerância à seca em espécies arbóreas (Poulson et al. 2002).

O objetivo deste trabalho foi avaliar os efeitos da radiação UV-B, em doses ambientais, sobre a morfologia foliar de Arabidopsis thaliana, espécie herbácea de crescimento rápido cujo ciclo de vida completa-se em torno de 30 dias.

\section{Material e métodos}

Sementes de Arabidopsis thaliana (L.) Heynh. ecótipo Columbia foram plantadas em tubos de plástico de centrífuga de $50 \mathrm{~cm}^{3}$. Os tubos foram preenchidos com uma mistura de 6:1 Premier ProMix PGX:areia. Premier ProMix PGX é um composto formado de turfa (60-70\%) e vermiculita (Premier Horticulture Inc., Red Hill PA). As sementes permaneceram na geladeira por 48 horas e depois de estabelecidas, as plântulas excedentes foram retiradas com o auxílio de uma pinça, permanecendo uma plântula por tubo, sendo estas regadas diariamente. As plântulas desenvolveram-se em câmaras de crescimento controlado (PGV 36, Conviron, Pembina ND, USA), mantidas a $24{ }^{\circ} \mathrm{C}$ durante o dia e $21^{\circ} \mathrm{C}$ durante a noite. A umidade relativa do ar na câmara oscilou entre $10 \%$ e $40 \%$. A radiação fotossinteticamente ativa (PAR) foi mantida em $300 \mu$ moles $\mathrm{m}^{-2} . \mathrm{s}^{-1}$ com um fotoperíodo de 12 horas, com a combinação de lâmpadas incandescentes e fluorescentes. A PAR foi determinada usando um sensor quantum (LI-250 LI-Cor Inc., Lincoln, NE). A radiação ultravioleta (UV-B) foi provida por bulbos 313 UV-B (Q-panel Lab Products, Cleveland, OH, USA), filtrados com folhas de "polyester" e acetato de celulose (Comcographics, Logan UT). As doses de radiação ultravioleta-B foram de 6 horas por dia $\left(6 \mathrm{~kJ} \mathrm{~m}^{-2} \mathrm{~d}^{-1}\right.$ UV-B $\left.{ }_{\text {be }}\right)$ de duração e medidas com um espectro biologicamente ativo (UV-B ${ }_{\text {be }}$; Caldwell 1971). As doses de UV-B foram determinadas, controlando a distância entre as lâmpadas e as plantas e medidas com um sensor de radiação UV-B (Solar Light Co., Philadelphia PA, USA). Após três semanas de crescimento, folhas totalmente expandidas foram coletadas para determinar as características morfológicas e bioquímicas. Para a massa fresca, 20 folhas totalmente expandidas, oriundas de 10 indivíduos de cada tratamento, foram pesadas em balança de precisão imediatamente após a coleta. Em seguida, as folhas foram secas em estufa à $70^{\circ} \mathrm{C}$, até peso constante. A área foliar dessas folhas foi calculada a partir da imagem escaneada em scanner de mesa (HewlettPackard, ScanJet 5100C, Greeley CO, USA), usando um software de calibração (Sigma Scan version 4.0, SPSS Inc., Chicago IL, USA). A área específica foliar (AEF) foi calculada utilizando a massa seca por unidade de área foliar $\left(\mathrm{mg} \cdot \mathrm{cm}^{-2}\right)$. As densidades de estômatos e de tricomas foram determinadas pela contagem dos mesmos, por $\mathrm{mm}^{2}$ nas superfícies abaxial e adaxial de 10 folhas previamente clarificadas com uma solução de ácido acético e água oxigenada 30 vol (1:1), durante 
três horas (Franklin 1945) e, posteriormente, coradas com azul de toluidina $0,05 \%$ em solução aquosa. As folhas foram montadas entre lâmina e lamínula e os estômatos e os tricomas contados a partir de imagens obtidas usando vídeo-câmara de alta resolução (SPOT Digital, Diagnostic Instruments Inc., Sterling Heights, MI) acoplada em microscópio de luz (Leica DM-R, Wetzlar, Switzerland). Para o estudo da anatomia foliar, porções da região mediana da folha foram fixadas em FAA 50 (ácido acético, formalina, álcool etílico 50\%, 1:1:18 (v/v)) (Johansen 1940). As secções foram desidratadas em série alcoólica etílica crescente e infiltradas com resina (Spurr 1969). Secções transversais $(3 \mu \mathrm{m})$ foram obtidas com ultra-micrótomo (RMC MT-7, Research and Manufacturing Co. Inc., Tucson, AZ), coradas com azul de toluidina $0,05 \% \mathrm{em}$ solução aquosa e montadas entre lâmina e lamínula com Etellanâ. A espessura total e do parênquima clorofiliano foram medidas em microscópio de luz com o auxílio de ocular micrométrica. Para a determinação da concentração de clorofila, foi utilizado $1 \mathrm{~cm}^{2}$ de tecido foliar, homogenizado em nitrogênio líquido e a clorofila extraída com acetona $80 \%$ (v/v). As concentrações de clorofila total, clorofila $a$ e clorofila $b$ foram determinadas espectrofotometricamente (espectrofotômetro Shimadzu, UV-2401PC), usando os coeficientes de extinção determinados por Porra et al. (1989). Os compostos fenólicos foram extraídos das folhas usando methanol acidificado (metanol:HCl:água, 90:1:1 (v/v) e quantificado espectrofotometricamente $\left(\mathrm{A}_{300 \mathrm{~nm}}\right)$, segundo a metodologia proposta por Markham (1982).

Para determinar se as características foliares eram estatisticamente significantes entre os dois tratamentos (com radiação UV-B e sem radiação UV-B), utilizouse o teste $\mathrm{t}$ com $5 \%$ de probabilidade, no programa Excel (versão 2003, Microsoft, USA).

\section{Resultados}

Os valores médios das características morfológicas foliares analisadas das plantas tratadas com UV-B ou sem radiação UV-B são apresentados na Tab. 1. Entre as características analisadas, apenas a densidade estomática da face adaxial da epiderme e a espessura da epiderme da face adaxial e da face abaxial não foram diferentes estatisticamente $(p<0,05)$ entre os dois tratamentos.

As folhas não tratadas com UV-B apresentaram os maiores valores médios de massa fresca, massa seca, área foliar, densidade estomática da epiderme da face abaxial e densidade de tricomas da epiderme na face adaxial do que as folhas tratadas com radiação UV-B.

Já as folhas que foram tratadas com UV-B apresentaram os maiores valores médios de área específica foliar (AEF), espessura total, do mesofilo, maior concentração de clorofila total, clorofila $a$ e clorofila $b$ quando comparadas com as folhas não tratadas com UV-B. As folhas tratadas com radiação UV-B apresentaram os bordos enrolados e voltados para a face abaxial (Fig. 1).

As folhas de ambos os tratamentos apresentaram compostos fenólicos nos tecidos foliares, no entanto, as folhas tratadas com radiação UV-B apresentaram maiores concentrações, por unidade de área, do que as folhas não tratadas com radiação UV-B.

A estrutura anatômica da lâmina foliar de A. thaliana é bastante simples e semelhante entre as plantas dos diferentes tratamentos. Em vista frontal, a epiderme é formada, em ambas as faces, por células com paredes sinuosas (Fig. 3 e 4). Os estômatos do tipo anomocítico (Fig. 3 e 4) ocorrem em ambas as faces, caracterizando a folha como anfiestomática, com maior número de estômatos, por unidade de área, ocorrendo na epiderme da face abaxial, em ambos os tratamentos. Os tricomas tectores são do tipo pluricelular ramificado (Fig. 2) e ocorrem tanto na face adaxial como na face abaxial da epiderme das folhas não tratadas com radiação UV-B. Nas folhas tratadas com UV-B, os tricomas ocorrem tanto sobre as nervuras, como nas regiões intercostais na face adaxial e somente sobre as nervuras da face abaxial.

Em secção transversal, a epiderme é unisseriada em ambas as faces, com cutícula fina (Fig. 5 e 6). As células epidérmicas variam no tamanho e formato. As células epidérmicas da face abaxial são mais achatadas, enquanto que na face adaxial ocorrem algumas células epidérmicas aproximadamente isodiamétricas entre as células achatadas (Fig. 5 e 6). Os estômatos, na face adaxial, são levemente elevados em relação às demais células epidérmicas. $\mathrm{O}$ mesofilo é constituído por cerca de quatro a seis camadas de células clorofiladas (Fig. 5 e 6). As duas camadas mais próximas à face adaxial são formadas por células mais ou menos isodiamétricas, sendo que a camada mais interna, nas plantas tratadas com UV-B, parece ser mais organizada do que as plantas não tratadas com UV-B. As camadas mais próximas à face abaxial possuem células mais largas, sendo que a largura da célula é quase duas vezes maior do que a sua altura. O mesofilo não é formado por parênquima paliçádico e lacunoso típicos, entretanto, observa-se diferenciação 
Tabela 1. Valores médios das características foliares quantitativas de Arabidopsis thaliana (L.) Heynh. tratadas sem radiação ultravioleta B (UV-B-) e com radiação ambiente (UV-B+). Valores entre parênteses representam o erro padrão. Letras diferentes na mesma linha indicam que as médias são estatisticamente significantes para o teste $\mathrm{t}(\mathrm{p}<0,05)$. Massa fresca e seca, área foliar e área específica foliar (AEF); densidade estomática, densidade de tricomas e espessuras total, do mesofilo e da epiderme da face adaxial a da face abaxial $(\mathrm{n}=10)$; compostos fenólicos, clorofila total, clorofila $a$ e $b$ e razão $a / b(\mathrm{n}=5)$.

\begin{tabular}{|c|c|c|}
\hline Características foliares & (UV-B-) & $(\mathrm{UV}-\mathrm{B}+)$ \\
\hline Massa fresca (mg) & $15,4(0,55) \mathrm{a}$ & $11,6(0,41) b$ \\
\hline Massa seca (mg) & $1,49(0,07) \mathrm{a}$ & $0,73(0,04) b$ \\
\hline Área foliar $\left(\mathrm{cm}^{2}\right)$ & $0,83(0,03) \mathrm{a}$ & $0,48(0,01) \mathrm{b}$ \\
\hline $\operatorname{AEF}\left(\mathrm{cm}^{2} \cdot \mathrm{g}^{-1}\right)$ & $0,59(0,03) \mathrm{b}$ & $0,71(0,05) \mathrm{a}$ \\
\hline Densidade estomática na epiderme adaxial $\left(\mathrm{n}^{\mathrm{o}} \cdot \mathrm{mm}^{-2}\right)$ & $278,0(22,8) a$ & $287,9(25,3) \mathrm{a}$ \\
\hline Densidade estomática na epiderme abaxial $\left(\mathrm{n}^{\mathrm{o}} . \mathrm{mm}^{-2}\right)$ & $376,9(17,8) a$ & $314,3(18) b$ \\
\hline Densidade de tricomas na epiderme adaxial $\left(\mathrm{n}^{\circ} \cdot \mathrm{mm}^{-2}\right)$ & $8,9(1,0) \mathrm{a}$ & $4,9(0,5) \mathrm{b}$ \\
\hline Densidade de tricomas na epiderme abaxial $\left(\mathrm{n}^{\mathrm{o}} \cdot \mathrm{mm}^{-2}\right)$ & $1,2(0.3) \mathrm{a}$ & $0(0) \mathrm{b}$ \\
\hline Espessura foliar total $(\mu \mathrm{m})$ & $126,0(5,7) b$ & $162,2(4,4) \mathrm{a}$ \\
\hline Espessura do mesofilo $(\mu \mathrm{m})$ & $99,3(5,2) \mathrm{b}$ & $128,3(2.6) \mathrm{a}$ \\
\hline Espessura da epiderme da face adaxial $(\mu \mathrm{m})$ & $17,9(4,4) \mathrm{a}$ & $22,1(5,1) \mathrm{a}$ \\
\hline Espessura da epiderme da face abaxial $(\mu \mathrm{m})$ & $11,5(2,5) \mathrm{a}$ & $10,0(1,6) \mathrm{a}$ \\
\hline Compostos fenólicos $\left(\mathrm{A}_{300 \mathrm{~nm}} \cdot \mathrm{cm}^{-2}\right)$ & $1,86(0,12) \mathrm{b}$ & $2,43(0,12) \mathrm{a}$ \\
\hline Clorofila total $\left(\mathrm{nmol} . \mathrm{cm}^{2}\right)$ & $34,18(2,27) \mathrm{b}$ & $76,61(1,54) \mathrm{a}$ \\
\hline Clorofila $a\left(\mathrm{nmol} . \mathrm{cm}^{-2}\right)$ & $23,13(0,60) b$ & $40,35(1,23) \mathrm{a}$ \\
\hline Clorofila $b\left(\mathrm{nmol} . \mathrm{cm}^{-2}\right)$ & $11,04(1,74) \mathrm{b}$ & $26,26(0,32) \mathrm{a}$ \\
\hline Razão clorofila $a b$ & $2,23(0,22) \mathrm{a}$ & $1,11(0,024) b$ \\
\hline
\end{tabular}

entre as camadas celulares, podendo-se assim classificar o mesofilo de dorsiventral.

Os feixes vasculares de pequeno porte, que ocorrem no mesofilo, apresentam poucos elementos de condução. A nervura central é caracterizada por um único feixe vascular, circundado por parênquima de preenchimento (Fig. 7 e 8). Nesta região, a epiderme também é unisseriada. Em posição subepidérmica, o colênquima é formado por poucas camadas de células. Não foram observadas diferenças estruturais, na região da nervura central, entre os tratamentos.

\section{Discussão}

A plasticidade fenotípica em resposta as condições ambientais estressantes tem sido reconhecida numa variedade de espécies vegetais (Mooney et al. 1991). A morfologia foliar, em particular, tem sido utilizada para elucidar os efeitos de fatores de estresse ambiental no desenvolvimento do órgão.

As variações estruturais e bioquímicas observadas em A. thaliana sob a ação da radiação UV-B indicam que a espécie é sensível a esta forma de radiação, como várias dicotiledôneas herbáceas (Day 1993; Gonzalez et al. 1998; Hao et al. 2000). Os menores valores médios de área foliar, massa fresca, massa seca e conteúdo de água encontrados nas folhas tratadas com
UV-B, também foram reportados para outras espécies (Correia et al. 1998; Poulson et al. 2002) e podem ser explicados como uma reação ao estresse provocado pela radiação nos processos de desenvolvimento e do metabolismo das plantas (Wellman 1983).

Os menores valores de área foliar para as plantas expostas a radiação, também podem ser entendidos como um mecanismo de proteção em função da redução do tamanho ou número de células (Gonzalez et al. 1998) ou ajustes na estrutura da folha (Tevini et al. 1983). A radiação UV-B exerce efeitos negativos sobre a divisão celular, o que também poderia resultar na menor área foliar (Nogués et al. 1998). Em Rumex patientia L., a ação da radiação UV-B parece inibir ou retardar a divisão celular (Dickson \& Caldwell 1978). Em cerca de $90 \%$ das plantas de interesse comercial tratadas com radiação UV-B, observou-se a diminuição da área foliar (Kakani et al. 2003a).

Nas plantas submetidas à radiação UV-B, os menores valores médios de biomassa, representados pela massa seca foliar, parecem ser o resultado da alocação de carbono para a biossíntese de metabólitos celulares, como por exemplo, os compostos fenólicos. Resultados semelhantes para outras espécies herbáceas indicam que o decréscimo de biomassa seca, associado ao incremento da concentração de compostos secundários pode ser utilizado como um 

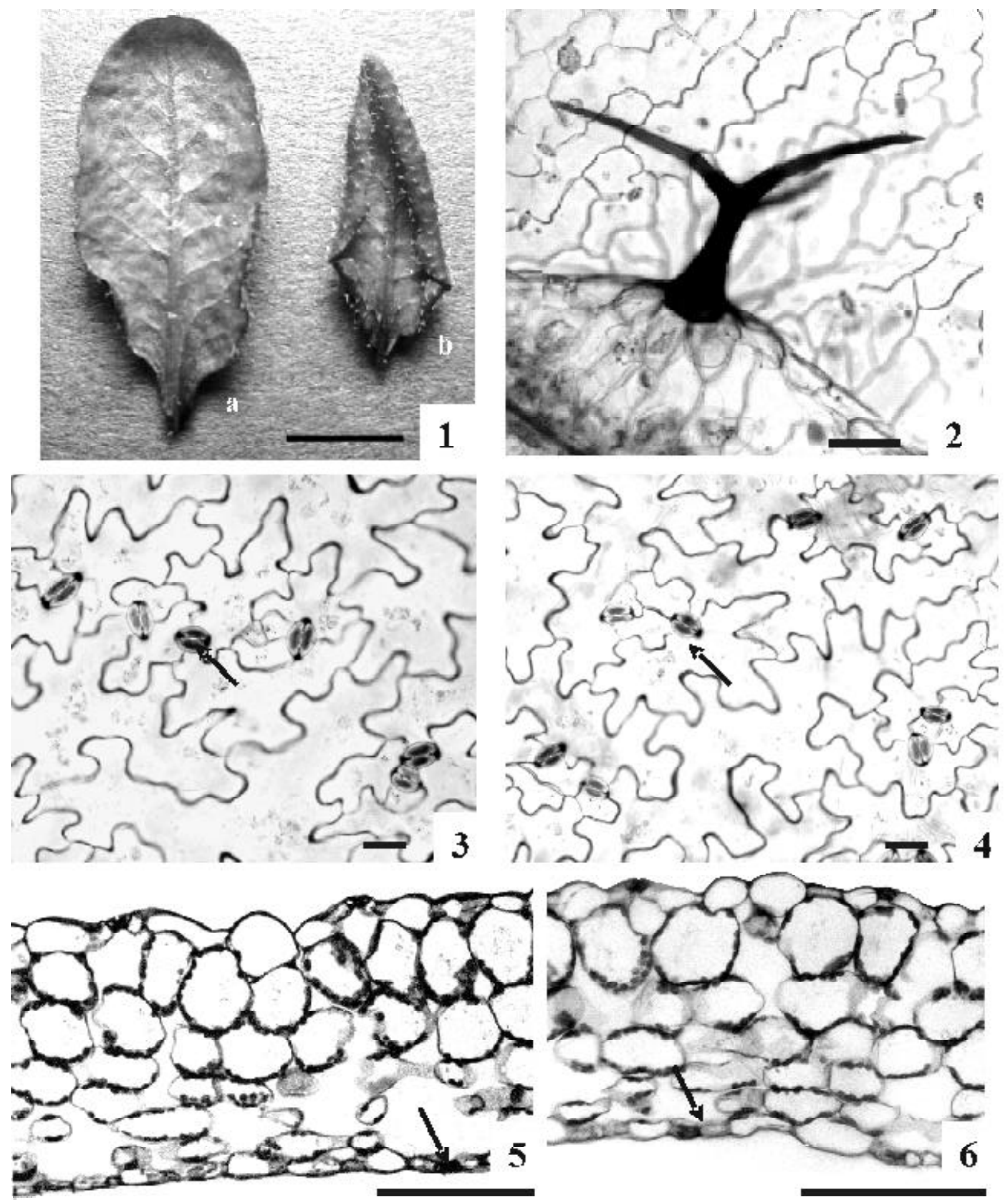

Figuras 1-6. 1. Folhas de Arabidopsis thaliana (L.) Heynh. após tratamento de 3 semanas com radiação UV-B. (a) sem tratamento (b) com tratamento. 2. Epiderme da face adaxial da folha sem tratamento de radiação UV-B, evidenciando tricoma tector ramificado. 3. Epiderme da face abaxial da folha tratada com radiação UV-B. 4. Epiderme da face abaxial da folha sem tratamento de radiação UV-B. 5. Secção transversal da folha tratada com radiação UV-B. 6. Secção transversal da folha tratada sem radiação UV-B. Seta nas figuras 3, 4 e 6 indica estômato. Fig. 1, barra =0,5 cm; Fig. 2 a 4, barra $=50 \mu \mathrm{m}$ e Fig. 5 e 6, barra $=100 \mu \mathrm{m}$. 


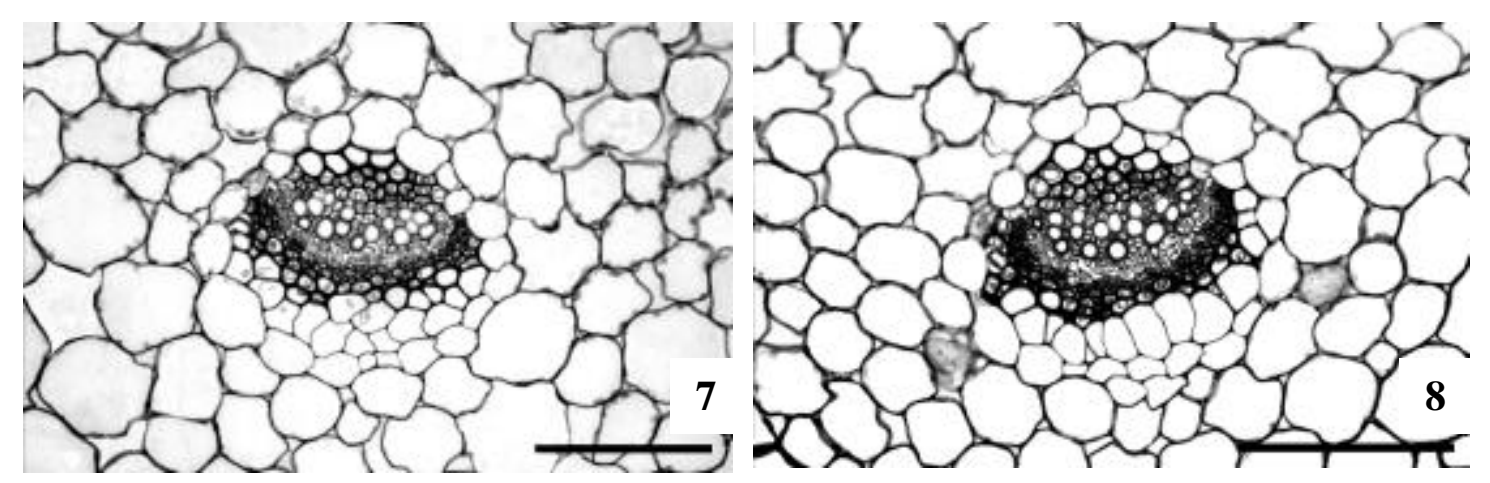

Figuras 7-8. 7. Secção transversal do feixe vascular da nervura da folha de Arabidopsis thaliana (L.) Heynh. sem radiação UV-B. 8. Secção transversal do feixe vascular da nervura da folha de $A$. thaliana tratada com radiação UV-B. Barra $=100 \mu \mathrm{m}$.

indicador da sensibilidade das plantas para radiação UV-B (Smith et al. 2000). Estas diferenças em biomassa também podem ser atribuídas ao efeito da radiação sobre expansão foliar, formando células menores e em menor número (Gonzales et al. 1998; Nogués et al. 1998). A redução da biomassa é freqüentemente citada na literatura com um dos indicadores confiáveis da sensibilidade das plantas à radiação UV-B, uma vez que representa os efeitos negativos e acumulativos da radiação sobre as funções fisiológicas (Smith et al. 2000).

Os maiores valores médios de AEF (área específica foliar) para as folhas tratadas com UV-B ocorreram em função da menor redução da massa seca foliar quando comparada com a redução da área foliar, que foi maior. Em decorrência disto, a relação AEF foi maior para as plantas tratadas com UV-B. A menor redução de massa seca foliar pode ter ocorrido em função do aumento da espessura da folha (Garnier \& Laurent 1994), pela adição de camadas do mesofilo, principalmente em folhas expostas a altas intensidades luminosas (Mendes et al. 2001).

O enrolamento das folhas de $A$. thaliana tratadas com UV-B também foi observado em outras espécies como uma resposta à radiação. Em Brassica napus L., o enrolamento está associado com a degradação da auxina na epiderme da face adaxial ou ainda, devido aos danos que a radiação causa às proteínas, ao DNA ou aos fotossistemas durante o desenvolvimento foliar (Wilson \& Greenberg 1993; Krol et al. 2000). O enrolamento das margens pode ser considerado como um mecanismo fotoprotetor das folhas para minimizar o efeito da radiação UV-B, uma vez que a área foliar exposta é menor.

Os maiores valores médios de densidade estomática da face abaxial das folhas não tratadas (em relação às folhas tratadas com UV-B) eram esperados, uma vez que vários estudos indicam que a radiação UV-B induz alterações estruturais e funcionais nos estômatos (Dai et al. 1995). Resultados similares de menores valores médios de densidade estomática, na face adaxial, foram encontrados para as folhas de Oryza sativa que se desenvolveram sob a ação da radiação UV-B (Dai et al. 1995). No entanto, resultados diferentes foram obtidos para algodão, onde folhas tratadas com alta dose de radiação UV-B $\left(16 \mathrm{kJm}^{-2} \cdot \mathrm{d}^{-1}\right)$ apresentaram maiores densidades estomáticas, em ambas as faces, do que as folhas controle (Kakani et al. 2003b). Segundo os autores, a radiação UV-B parece afetar as plantas de maneira similar ao déficit hídrico, reduzindo a área foliar e ao estresse térmico, aumentando a densidade estomática. Estudos com folhas de ervilha mostraram que folhas tratadas com radiação UV-B antes e depois da expansão celular apresentaram densidades estomáticas diferenciadas. A densidade estomática das folhas tratadas com UV-B foi maior nas folhas imaturas. Já as folhas totalmente expandidas, tratadas com UV-B e as folhas controle, não apresentaram diferenças significantes quanto à densidade estomática (Nogués et al. 1998). No nosso estudo, onde também foram utilizadas folhas totalmente expandidas, não houve diferenças significativas, para a densidade estomática da face adaxial, entre as folhas tratadas com UV-B e as não tratadas. Este resultado não era esperado, uma vez que a face adaxial da folha está mais exposta a radiação do que a face abaxial. As informações para a variação da densidade estomática de folhas sob o efeito da radiação UV-B são inconclusivas e as inconsistências encontradas entre os diversos estudos podem ser devido às respostas específicas de cada espécie; diferenças na idade da folha ou em função 
dos diferentes tipos de tratamentos com radiação UV-B (Jansen \& Noort 2000; Poulson et al. 2002).

A ocorrência de uma densa camada de tricomas sobre a folha, principalmente na face adaxial tem sido reportada por alguns autores como uma barreira eficiente contra a radiação UV-B, devido à presença de substâncias absorventes de radiação UV-B nas células dos tricomas (Petropoulou et al. 1995; Liakoura et al. 1997). Entretanto, para A. thaliana, a radiação UV-B parece ter inibido a formação de tricomas na epiderme em ambas as faces. Alguns estudos indicam que a formação de tricomas, principalmente da face adaxial parece ser regulada, diferentemente da formação de tricomas da face abaxial, por fitohormônios como a giberelina (Telfer et al. 1997; Traw \& Bergelson 2003). Devido a diferenças fisiológicas entre as duas faces da folha, a formação de tricomas na face abaxial é mais tardia durante o desenvolvimento foliar (Chien \& Sussex 1996; Telfer et al. 1997). Provavelmente, a ausência de tricomas na face adaxial das folhas tratadas com UV-B, seja resultado do efeito direto e negativo da radiação UV-B associado à ação dos fitohormônios sobre as células da protoderme durante o desenvolvimento foliar. $\mathrm{Na}$ face abaxial, as células da epiderme estão mais protegidas da ação da radiação UV-B e, possivelmente, o efeito da radiação sobre a formação dos tricomas foi menos deletério do que na face adaxial da folha.

A espessura média total das folhas tratadas com radiação UV-B e a espessura do mesofilo foram maiores quando comparadas com as folhas não tratadas com UV-B. Folhas mais espessas, juntamente com a menor área foliar, também são entendidas como uma resposta às diferentes condições de estresse (Lambers et al. 1998). A espessura e a área foliar, nessas circunstâncias, tendem a ser inversamente proporcionais e compensatórias entre si. A folha diminui a área exposta, mas aumenta a espessura da lâmina, devido ao incremento dos tecidos fotossintéticos e dos espaços intercelulares, garantindo assim o volume da folha (Lewis 1972; Smith et al. 1997). Maior espessura também foi reportada para outras espécies estudadas sob a influência da radiação UV-B (Cen \& Bornman 1993; Kakani et al. 2003a), apesar de resultados contrários serem reportados na literatura (Correia et al. 1998; Kakani et al. 2003b).

$\mathrm{O}$ maior valor médio da espessura das folhas tratadas com UV-B parece ser um importante elemento para diminuir a penetração da radiação no interior da folha. Folhas mais espessas possuem um maior número de camadas de células ou células maiores, o que aumenta a área da parede celular, minimizando a ação da radiação UV-B nas camadas do mesofilo fotossinteticamente ativo próximo à face abaxial (Cen \& Bornman 1993). O aumento de espessura proporciona também, um maior número de espaços intercelulares, o que afeta a transmitância da luz incidente (luz difusa) no interior da folha (Bornman \& Vogelmann 1991). Entretanto, alguns estudos têm demonstrado que a espessura da folha não é o único fator que pode reduzir a ação da radiação no interior da folha (Cen \& Bornman 1993; Day 1993). A composição química da cutícula (Pilon et al. 1999), assim como, a presença de compostos fenólicos parece exercer importante função na reflexão da radiação UVB na superfície da folha (Day et al. 1992; Day 1993).

A presença de compostos fenólicos nas folhas tratadas com radiação UV-B pode atenuar o efeito da radiação. Porém, o local e a uniformidade dos compostos fenólicos são importantes para determinar a sua eficiência (Day et al. 1992; Liakoura et al. 2003). As folhas A. thaliana, sob a ação da radiação UV-B, apresentaram maiores concentrações de compostos fenólicos do que as plantas controle, mas não foi possível detectar, entre os tecidos foliares, aqueles que tem maior concentração destes compostos. Vários estudos indicam que os compostos fenólicos podem formar uma barreira eficaz contra a radiação UV-B quando se localizam de maneira uniforme nas paredes anticlinais das células epidérmicas (Day 1993; Poulson et al. 2002). Em plantas herbáceas, os estudos indicam ainda que os compostos fenólicos localizam-se primariamente no protoplasto das células epidérmicas (Day et al. 1992) e em concentrações bem mais baixas do que nas paredes celulares das coníferas. No entanto, concentrações significativas podem ocorrer no mesofilo de algumas espécies (Day 1993). Independente da região foliar nas quais estes compostos ocorrem, a radiação UV-B parece induzir a produção de compostos fenólicos nas folhas de várias espécies vegetais (Day 1993; Hoque \& Remus 1999; Laakso et al. 2000), como um mecanismo fotoprotetor. Neste estudo, as maiores concentrações de compostos fenólicos nas folhas tratadas com UV-B também podem ser resultante da maior espessura da lâmina, uma vez que os valores médios destes compostos foram calculados por unidade de área.

As concentrações de clorofila total, clorofila $a$ e $b$ nas folhas tratadas com radiação UV-B apresentaram menores valores médios, quando comparadas com as folhas não tratadas com radiação UV-B, para várias espécies estudadas, em função da ruptura dos tilacóides e a desintegração de suas membranas (Kakani et al 
2003a). Os resultados obtidos para A. thaliana contrariam esta tendência, juntamente com outros estudos que obtiveram resultados semelhantes (Caldwell et al. 1982; Tevini et al. 1989). Os estudos que abordam a relação entre as concentrações de clorofila com radiação UV-B ainda são controversos. Alguns autores sugerem que plantas tratadas com radiação UV-B e que apresentam maiores concentrações de clorofila parecem ser mais tolerantes à radiação (Bornman \& Vogelmann 1991; Greenberg et al. 1997). Outros autores sugerem que plantas de crescimento rápido, como A. thaliana, são mais sensíveis à radiação e tendem a ter menores concentrações de clorofila (Barnes et al. 1990), enquanto que outros consideram que as maiores concentrações de clorofila, juntamente com as maiores concentrações de compostos fenólicos, podem ser indicadores da resposta da planta à radiação, mas não um indicador de sensibilidade (Smith et al. 2000).

Os resultados aqui apresentados indicam que as folhas de A. thaliana, que se desenvolveram sob a radiação UV-B, apresentam mudanças estruturais e bioquímicas, representadas pelos maiores valores médios de área e massa foliar, AEF, densidade estomática e de tricomas, espessura total e do mesofilo, concentração de compostos fenólicos e de clorofila quando comparadas com as folhas não tratadas com radiação UV-B. Estas mudanças estruturais sugerem que $A$. thaliana é sensível à radiação e possui mecanismos de fotoproteção para minimizar os seus efeitos negativos sobre o desenvolvimento e crescimento foliar.

Entretanto, as respostas da planta à radiação envolvem vários mecanismos fisiológicos que devem ser elucidados. Além disso, os dados aqui apresentados mostraram as respostas da espécie sob uma única dosagem de radiação UV-B. Outros experimentos utilizando outras dosagens de radiação, combinadas com diferentes irradiâncias e suprimento hídrico, podem gerar informações importantes para o entendimento sobre o crescimento e desenvolvimento de espécies vegetais em condições mais adversas, como o aumento da radiação ultravioleta sobre a superfície terrestre.

\section{Agradecimentos}

As autoras agradecem ao Departamento de Ciências Biológicas da Idaho State University, Pocatello, ID, USA, pelo uso dos laboratórios; a Julie Kovalinka, pelo auxílio nas análises de clorofila e compostos fenólicos; ao Biólogo Nilson Belém Filho, pela confecção das lâminas permanentes; a Walter A.
Boeger, pelo auxílio no uso dos equipamentos de captura de imagem e revisão do Abstract.

\section{Referências bibliográficas}

Allen, D.J.; Nogués, S. \& Baker, N.R. 1998. Ozone depletion and increased UV-B radiation: is there a real threat to photosynthesis? Journal of Experimental Botany 49: 1775-1788.

Barnes, P.W.; Flint, S.D. \& Caldwell, M.M. 1990. Morphological responses of crop and weed species of different growth forms to ultraviolet radiation. American Journal of Botany 77: 1354-1360.

Bornman, J.F. \& Vogelmann, T.C. 1991. Effect of UV-B radiation on leaf optical properties measured with fiber optics. Journal of Experimental Botany 42: 547-554.

Caldwell, M.M. 1971. Solar UV irradiation and the growth and development of higher plants. In: Photophysiology v. 6. New York, Academic Press.

Caldwell, M.M.; Robberecht, R.; Nowak, R.S. \& Billings, W.D. 1982. Differential photosynthetic inhibition by ultraviolet radiation in species from the artic-alpine life zone. Artic and Alpine Research 14: 195-202.

Cen, Y. \& Bornman, J.F. 1993. The effect of exposure to enhanced UV-B radiation on the penetration of monochromatic and polychromatic UV-B radiation in leaves of Brassica napus. Physiologia Plantarum 87: 249-255.

Chien, J.C. \& Sussex, I.M. 1996. Differential regulation of trichome formation on the adaxial and abaxial leaf surfaces by gibberellins and photoperiod inArabidopsis thaliana (L.). Plant Physiology 111: 1321-1328.

Correia, C.M.; Areal, E.L.V.; Torres-Pereira, M.S. \& TorresPereira, J.M.G. 1998. Intraspecific variation in sensitivity to ultraviolet-B radiation in maize grown under field conditions. I. Growth and morphological aspects. Field Crops Research 59: 81-89.

Dai, Q.; Peng, S.; Chavez, A.Q. \& Vergara, B.S. 1995. Effects of UV-B radiation on stomatal density and opening in rice (Oryza sativa L.). Annals of Botany 76: 65-70.

Day, T.A. 1993. Relating UV-B radiation screening effectiveness of foliage to absorbing-compound concentration and anatomical characteristics in a diverse group of plants. Oecologia 95: 542-550.

Day, T.A.; Vogelmann, T.C. \& DeLucia, E.H. 1992. Are some plant life forms more effective than others in screening out ultraviolet-B radiation? Oecologia 92: 513-519.

Day, T.A. \& Vogelmann, T.C. 1995. Alterations in photosynthesis and pigment distributions in pea leaves following UV-B exposure. Physiologia Plantarum 94: 433-440.

Dickson, J.G. \& Caldwell, M.M. 1978. Leaf development of Rumex patientia L. (Polygonaceae) exposed to UV irradiation (280-320 nm). American Journal of Botany 65:857-863.

Franklin, G.L. 1945. Preparation of thin sections of synthetic resins and wood-resin composites, and a new macerating method for wood. Nature 155: 51. 
Garnier, E. \& Laurent, G. 1994. Leaf anatomy, specific mass and water content in congeneric annual and perennial grass species. New Phytologist 128: 725-736.

Gonzalez, R.; Mepsted, R.; Wellburn, A.R. \& Paul, N.D. 1998. Non-photosynthetic mechanisms of growth reduction in pea (Pisum sativum L.) exposed to UV-B radiation. Plant, Cell and Environment 21: 23-32.

Greenberg, B.M.; Wilson, M.I.; Huang, X.D.; Duxbury, C.L. Garhardt K.E. \& Gensemer, R.W. 1997. The effects of ultraviolet-B radiation on higher plants. In: W. Wang; J.W. Gorsuch \& J.S. Hughes (eds.). Plants for environmental studies. Boca Raton, CRC Press.

Hao, X.; Hale, B.A.; Ormrod, D.P. \& Papadopoulos, A.P. 2000. Effects of pre-exposure to ultraviolet-B radiation on responses of tomato (Lycopersicon esculentum cv. New Yorker) to ozone in ambient and elevated carbon dioxide. Environmental Pollution 110: 217-224.

Hoque, E. \& Remus, G 1999. Natural UV-screening mechanisms of Norway spruce (Picea abies [L.] Karst.) needles. Photochemistry and Photobiology 69: 177-192.

Jansen, M.A.K.; Gaba, V. \& Greenberg, B.M. 1998. Higher plants and UV-B radiation: balancing damage, repair and acclimation. Trends in Plant Science 3: 131-135.

Jansen, M.A.K. \& Noort, R.E. van der. 2000. Ultraviolet-B radiation induces complex alterations in stomatal behaviour. Physiologia Plantarum 110: 189-194.

Johansen, D.A. 1940. Plant Microtechnique. New York, Mc Graw Hill Book.

Jordan, B.R. 1996. The effects of ultraviolet-B radiation in plants: a molecular perspective. Advances in Botanical Research 22: 97-161.

Kakani, V.G.; Reddy, K.R.; Zhao, D. \& Sailaja, K. 2003a. Field crop responses to ultraviolet-B radiation: a review. Agricultural and Forest Meteorology 120: 191-218.

Kakani, V.G.; Reddy, K.R.; Zhao, D. \& Mohammed, A.R. 2003 b. Effects of ultraviolet-radiation on cotton (Gossypium hirsutum L.) morphology and anatomy. Annals of Botany 91: 817-826.

Kerr, R.A. 1993. The ozone hole reaches a new low.Science 262: 501.

Krol, P.M.; Ormrod, D.P.; Binder, W.D. \& L'Hirondelle, S.J. 2000. Effects of ultraviolet-B radiation on needle anatomy and morphology of Western Larch, Interior Spruce and Lodgepole Pine. Journal of Sustainable Forestry 10: 141-148.

Laakso, K.; Sullivan, J.H. \& Huttunen, S. 2000. The effects of UV-B-radiation on epidermal anatomy in loblolly pine (Pinus taeda L.) and Scots pine (Pinus sylvestris L.). Plant, Cell and Environment 23: 461-472.

Lambers, H.; Chapin III, F.S. \& Pons, T.L. 1998. Plant Physiological Ecology. New York, Springer-Verlag.

Lewis, M.G 1972. The physiological significance of variation in leaf structure. Science Progress 60: 25-51.

Liakoura, V.; Stefanou, M.; Manetas, Y.; Cholevas, C. \& Karabourniotis, G. 1997. Trichome density and its UV-B protective potential are affected by shading and leaf position on the canopy. Environmental and Experimental Botany 38: 223-229.
Liakoura, V.; Bornean, J.F. \& Karabourniotis, G. 2003. The ability of abaxial and adaxial epidermis of sun and shade leaves to attenuate UV-A and UV-B radiation in relation to the UV absorbing capacity of the whole leaf methanolic extracts. Physiologia Plantarum 117:33-43.

Markham, K.R. 1982. Technics of flavonoid identification. London, Academic Press.

Mazza, C.A.; Boccalandro, H.E.; Giordano, C.V.; Battista, D.; Scopel A.L. \& Ballaré, C.L. 2000. Functional significance and induction by solar radiation of ultraviolet-absorbing sunscreens in field-grown soybean crops. Plant Physiology 122: 117-125.

Mendes, M.M.; Gazarini, L.C. \& Rodrigues, M.L. 2001. Acclimation of Myrtus communis to contrasting Mediterranean light environments - effects on structure and chemical composition of foliage and plant water relations. Environmental and Experimental Botany 45 : 165-178.

Mooney, H.A.; Winner, W.E.; Pell, E.J. \& Chu, E. 1991. Response of plants to multiple stresses. San Diego, Academic Press.

Nagel, L.M.; Bassman, J.H.; Edwards, G.E.; Robberecht, R. \& Franceshi, V.R. 1998. Leaf anatomical changes inPopulus trichocarpa, Quercus rubra, Pseudotsuga menziesii and Pinus ponderosa exposed to enhanced ultraviolet-B radiation. Physiologia Plantarum 104: 385-396.

Nogués, S.; Allen, D.J.; Morison J.I.L. \& Baker, N.R. 1998. Ultraviolet-B radiation effects on water relations, leaf development, and photosynthesis in droughted pea plants. Plant Physiology 117: 173-181.

Parisi, A.V.; Wong J.C.F. \& Galea, V.J. 1998. A study of the total ultraviolet exposure to all the leaves for small-plant growth. Journal of Photochemistry and Photobiology B: Biology 45: 36-42.

Petropoulou, Y.; Kyparissis, A.; Nikolopoulos, D. \& Manetas, Y. 1995. Enhanced UV-B radiation alleviates the adverse effects of summer drought in two Mediterranean pines under field conditions. Physiologia Plantarum 94: $37-44$.

Pilon, J.J.; Lambers, H.; Baas, W.; Tosserams, M.; Rozema, J. \& Atkin, O.K. 1999. Leaf waxes of slow-growing alpine and fast-growing lowland Poa species: inherent diferences and responses to UV-B radiation. Phytochemistry 50: 571-580.

Porra, R.J.; Thompson, W.A. \& Kriedemann; P.E. 1989. Determination of accurate extinction coefficients and simultaneous equations for assaying chlorophylls $a$ and $b$ extracted with four different solvents: verification of the concentration of chlorophyll standards by atomic absorption spectroscopy. Biochimica et Biophysica Acta 975: 384-394.

Poulson,M.E.; Donahue R.A.; Konvalinka, J. \& Boeger, M.R.T. 2002. Enhanced tolerance of photosynthesis to high-light and drought stress inPseudotsuga menziesii seedlings grown in ultraviolet-B radiation. Tree Physiology 22: 829-838.

Smith, W.K.; Vogelmann, T.C.; DeLucia, E.H.; Bell; D.T. \& Shepherd, K.A. 1997. Leaf form and photosynthesis. Bioscience 47: 785-793. 
Smith, J.L.; Burritt, D.J. \& Bannister, P. 2000. Shoot dry weight, chlorophyll and UV-B absorbing compounds as indicators of a plant's sensitivity to UV-B radiation. Annals of Botany 86: 1057-1063.

Spurr, A.R. 1969. A low-viscosity epoxy resin embedding medium for electron microscopy. Journal of Ultrastructure Research 26: 31-43.

Stapleton, A.E. 1992. Ultraviolet radiation and plants: burning questions. The Plant Cell 105: 881-889.

Telfer, A.; Bollman, K. \& Poethig, R. 1997. Phase change and the regulation of trichome distribution in Arabidopsis thaliana. Development 124(3): 645-654.

Tevini, M.; Thoma, U. \& Iwanzik, W. 1983. Effects of UV-B radiation on germination, seedling growth, leaf anatomy, and pigments of some crop plants. Zeitschrift fur Pflanzenzuchtung 109: 435-448.
Tevini, M. \& Teramura, A.H. 1989. UV-B effects in terrestrial plants. Photochemistry and Photobiology 50: 479-487.

Tosserams, M. \& Rozema, J. 1995. Effects of ultraviolet-B radiation (UV-B) on growth and physiology of the dune grassland species Calamagrostis epigeios. Environmental Pollution 89(2): 209-214.

Traw, B.M. \& Bergelson, J.2003. Interactive effects of jasmonic acid, salicylic acid, and gibberellin on induction of trichomes in Arabidopsis. Plant Physiology 133: 1367-1375.

Wellman, E. 1983. UV radiation in photomorphogenisis. In: W. Shropshire \& H. Mohr (eds.). Encyclopedia of Plant Physiology. New Series. Photomorphogenesis. Berlin, Springer.

Wilson, M.I. \& Greenberg, B.M. 1993. Specificity and photomorphogenic nature of ultraviolet-B-induced cotyledon curling in Brassica napus L.Plant Physiology 102: 671-677. 